\title{
Clinical Characteristics of People Who Attempted Suicide by Carbon Monoxide Poisoning in Korea
}

\author{
Hwayeon Jo, MD, PhD', Kounseok Lee, MD, PhD', Sujin Son, MD¹, Hyunggoo Kang, MD, PhD², \\ Seokhyeon Kim, MD, PhD', Sungwon Roh, MD, $\mathrm{PhD}^{1}$ \\ ${ }^{1}$ Department of Psychiatry, Hanyang University College of Medicine, ${ }^{2}$ Department of Emergency Medicine, Hanyang University College of \\ Medicine, Seoul, Korea
}

\begin{abstract}
Background: The rate of suicide by carbon monoxide (CO) poisoning is increasing rapidly in Korea. In this study, we aimed to investigate the clinical characteristics of suicide attempters in Korea and to identify risk groups for choosing CO poisoning as a suicide method.

Methods: Patients who visited the emergency department after attempting suicide between April 2017 and June 2019 were included in this study. We reviewed the medical records and evaluated the demographic and clinical data of suicide attempters. Cross-tabulation analyses and multivariable logistic regression analyses were performed.

Results: Statistically significant risk groups for suicide by CO poisoning were men (odds ratios [OR], 1.71), those who were 25-44 years of age (OR, 7.35), those with no psychiatric history $(\mathrm{OR}, 2.12)$, and those who made a suicide plan (OR, 7.70). Among suicide attempters grouped according to psychiatric diagnoses, those with adjustment disorders were most likely and those with psychosis were least likely to choose $\mathrm{CO}$ poisoning as the suicide method.

Conclusion: To prevent a CO poisoning suicide attempt, it seems warranted to develop a tool to screen patients for suicide risk as part of a regular health checkup so that early intervention can be provided.
\end{abstract}

Keywords Carbon monoxide poisoning; Suicide; Clinical characteristics; Risk; Charcoal

\section{INTRODUCTION}

Suicide is a major problem worldwide and can occur throughout life. According to the World Health Organization, 800,000 people die each year from suicide, which is equivalent to one death due to suicide every $40 \mathrm{sec}-$ onds [1]. In particular, Korea has ranked first in suicide rates among members of the Organization for Economic Cooperation and Development (OECD) since 2003. In terms of the age-standardized suicide rate among OECD countries, Korea recorded more than double the number of suicide attempts at 24.7 per 100,000 population compared to the OECD average of 11.5 per 100,000 population [2]. The Korean National Statistical Office reported 13,670 deaths due to suicide in 2018, i.e., an average of 37.5 deaths per day, with an annual suicide rate of 26.6 per 100,000 population. The rate of CO poisoning suicide was 4.2 per 100,000 population, accounting for more than $10 \%$ of suicide annually; it was the third most commonly used method, after hanging (13.9 per 100,000 population) and jumping (4.4 per 100,000 population) [3]. Suicide is the fifth largest cause of death in Korea after malignant neoplasms, heart disease, cerebrovascular disease, and pneumonia. It is also the number one cause of death among teenagers and people in their $30 \mathrm{~s}$, with the highest number of suicide deaths in their 40s and 50s [4]. It is estimated that an economic loss of about 6 billion USD can be avoided in Korea by suicide prevention [5]. While suicide prevention is a major concern not only for individuals but also for the nation [6], suicide continues

Received October 27, 2020, Revised November 5, 2020, Accepted November 5, 2020

Correspondence: Sungwon Roh, MD, PhD

Department of Psychiatry, Hanyang University College of Medicine, 222 Wangsimni-ro, Seongdong-gu, Seoul 04763, Korea

TEL +82-2-2290-8422 FAX +82-2-2298-2055 E-mail swroh@hanyang.ac.kr ORCID https://orcid.org/0000-0003-4557-3542

Copyright $@$ by Korean Society for Affective Disorders. All Rights reserved.

This is an Open Access article distributed under the terms of the Creative Commons Attribution Non-Commercial License (http://creativecommons.org/licenses/ by-nc/4.0/) which permits unrestricted non-commercial use, distribution, and reproduction in any medium, provided the original work is properly cited. 
to be a social problem as well as a mental health risk.

Drug poisoning, pesticide poisoning, jumping from a height, hanging, and carbon monoxide $(\mathrm{CO})$ poisoning are among the relatively common methods used by suicide attempters in Korea [7,8]. Among them, CO poisoning is one of the most commonly attempted suicide methods in Korea $[7,8]$, which is similar to that reported in previous studies from Asia [9-11]. Detailed media coverage of suicide incidents including a vivid portrayal of $\mathrm{CO}$ poisoning as a painless, non-violent suicide method is attributed to a rapid gain of popularity of CO poisoning in Hong Kong since 1988 [10,12,13]. It affected not only Hong Kong but also the neighboring countries and spread in a short time. In Taiwan, the suicide rate had increased by $150 \%$ from 1995 to 2006 . CO poisoning rapidly surpassed other suicide methods and became the leading cause of suicide deaths [14]. A similar phenomenon occurred in Korea. In Korea, suicide attempts using $\mathrm{CO}$ poisoning accounted for $0.7 \%$ of all suicide cases reported in 2007. However, after a celebrity in Korea killed himself by burning ignition coal in an enclosed car in 2008, the media reported the method in detail, which was followed by a rapid rise in the rate of suicide using a similar method [15-17]. By 2013, CO poisoning had become the third most frequently used suicide method after substance poisoning (drugs, pesticides, etc.) and self-harm by sharp objects in Korea with the rate of suicide attempts by $\mathrm{CO}$ poisoning being $8.2 \%$ that further increased to $10.3 \%$ by $2018[7,8]$.

Given the increasing suicide attempts with $\mathrm{CO}$ poisoning, prevention of suicide by $\mathrm{CO}$ poisoning may affect future suicide rates. Therefore, it would be important to determine who would more likely use $\mathrm{CO}$ poisoning as the suicide method and intervene quickly. In Taiwan, the rate of suicide by CO poisoning increased from 1995 to 2006 in people younger than 65 years, especially those aged between 25 and 44 years, male, and divorced or unmarried people [14]. In another study, when comparing people who used CO poisoning and those who ingested poison among suicide survivors, the former had a higher level of suicide intent [11]. In Hong Kong, a higher risk of $\mathrm{CO}$ poisoning suicide was also found among male aged 25-54 years. Suicide attempters using CO poisoning were more likely to have planned the suicide act as it requires the relevant tools and place. Also, they were more likely economically active but experiencing financial difficulties [10].

Because suicide attempts with $\mathrm{CO}$ poisoning require planning, we suspected that those who use CO poisoning more likely have relatively steady mood status rather than fluctuating emotional status. However, the vast majority of prior studies were based on retrospectively collected national suicide statistics that often lack information on the psychiatric history and/or diagnosis. Although some studies have compared clinical features including psychiatric diagnosis $[9,10,18]$, the sample size in individual studies was relatively small. To this end, we aimed to evaluate the difference in clinical characteristics of suicide attempters between those who employed CO poisoning and those who employed other methods using a large sample size obtained in an actual emergency room clinical setting.

\section{MATERIALS AND METHODS}

This study included suicide attempters who visited the Emergency Department (ED) of Hanyang University Hospital in Seoul from April 1, 2017, to June 30, 2019. Since 2017, an ED-based case management project has been conducted by a team called "Saving Life Team (SLT)," which comprised three trained social workers (called 'SLT case managers' within the team), six psychiatrists, and 10 emergency medicine physicians. Suicide attempters transported to the ED were assessed for any pre-existing physical problems and received first aid treatment as necessary. After that, the ED consulted with the SLT and psychiatry department. A psychiatrist who was trained in the interview skills based on the Structured Clinical Interview of the Diagnostic and Statistical Manual of Mental Disorder (DSM-V) conducted a face-to-face interview with the patients and documented their findings in a medical record. SLT case managers also performed initial assessments based on the structured questionnaire. The recorded data were collected and analyzed.

\section{Participants and assessments}

After excluding 21 patients who died before medi$\mathrm{cal} /$ psychiatric assessment was made in the ED, 1,039 suicide attempters were enrolled in the study. Among these, 59 patients visited the ED more than once due to repeated suicide attempts. In these 59 patients, only information obtained during the final visit to the ED was included in this study. 
Psychiatric diagnoses of the patients were made and classified into main categories based on the 5th edition of the DSM-V, text revision [19]. As most cases of bipolar and related disorders were related to depressive episodes, they were classified as mood disorders along with those with depressive disorders. As the proportion of adjustment disorders is overwhelming among traumaand stressor-related disorders, adjustment disorder is classified separately. Cases in which a diagnosis cannot be specified were classified as 'unspecified'.

Based on the International Classification of Diseases, Tenth Revision, suicide methods were classified into suicide using CO (and other gases and vapors) (X67) and other suicide methods [20]. Other methods of suicide attempts included hanging, drowning, jumping, drug poisoning, pesticide poisoning, and self-harm by sharp objects. For each record, the following clinical characteristics of the patients were reviewed: age, sex, occupation, marital status, history of suicide attempt, history of psychiatric diagnoses, and psychiatric diagnosis at the time of ED visit.

The patients were divided into 4 age groups $(\leq 24,25$ $44,45-64$, and $>65$ years), two groups according to sex, 4 groups according to the duration of schooling $(\leq 6,7-9$, $10-12$, and $>12$ years), 4 groups according to the marital status (single, married, divorced/separated/widowed, and cohabitation), 3 groups according to the status of economic activity (employed, unemployed, and student/ housewives), 2 groups according to the presence or absence psychiatric history, and 2 groups according to the presence or absence of suicide attempt history. We also assessed whether the suicide attempt followed a plan or was impulsive. The patient was considered having a plan if his/her response to the question, "Have you started to work out or worked out the details of how to kill yourself?" was 'yes'.

\section{Statistical analyses}

Categorical data are presented as frequencies and percentages, while continuous variables are expressed as means and standard deviations. The groups that used CO poisoning and other suicide methods were compared. To determine the between-group differences, categorical variables were analyzed using the Fisher's exact test or chi-square test when computation using the Fisher's exact test is not feasible.

A univariable logistic regression analysis was per- formed followed by a multivariable logistic regression analysis to determine significant predictor variables of suicide attempts using $\mathrm{CO}$ poisoning. Suicide attempts using $\mathrm{CO}$ poisoning and those using other methods were coded as binary outcome variables.

All statistical analyses were performed using IBM SPSS Statistics for Windows, Version 24.0 (IBM Co., Armonk, NY, USA). The significance level was defined as $\mathrm{p}<0.05$.

\section{Ethics}

The research was approved in written informed consent by the Institutional Review Board of the Hanyang University Hospital (IRB. No. 2020-01-021-001).

\section{RESULTS}

\section{Patients' demographic characteristics}

Of the 1,039 patients, 479 were male (46.1\%), and 560 were female (53.9\%). The patients' ages ranged from 12 years to 92 years with a mean of $40.1 \pm 17.9$ years.

The rate of suicide attempts by intentional self-poisoning with drugs was the highest (45\%), followed by CO poisoning (36\%), stabbing (11\%), hanging (5\%), jumping $(2 \%)$, and others (1\%). Approximately $60 \%$ of the suicide attempters were diagnosed with mood disorders including major depressive disorder and bipolar disorder by psychiatrists at the time of ED visit.

\section{Clinical features of the $\mathrm{CO}$ group and non-CO group}

A total of 377 patients (36\%) attempted suicide by $\mathrm{CO}$ poisoning all of whom used coal-burning to generate $\mathrm{CO}$ (hereafter referred to as the CO group), while 762 (64\%) used other methods (hereafter referred to as the non-CO group). Table 1 shows the rates of suicide attempts by means of $\mathrm{CO}$ poisoning vs. other methods in clinical subgroups divided according to sex, age group, education years, marital status, economic activity, previous suicide attempt history, and planned vs. impulsive attempt of suicide.

Of the 479 male patients, $49 \%$ attempted suicide by CO poisoning, while only $26 \%$ of the 560 female patients did so $(p<0.0001)$. Approximately, $45 \%$ of the 
Table 1. Clinical characteristics of the $\mathrm{CO}$ group and non-CO methods group

\begin{tabular}{|c|c|c|c|}
\hline \multirow{2}{*}{ Clinical characteristics } & \multicolumn{2}{|c|}{ Suicide methods } & \multirow{2}{*}{$\mathrm{p}$-value } \\
\hline & CO poisoning $(n=377)$ & Non-CO methods ( $n=762)$ & \\
\hline \multicolumn{4}{|l|}{ Sex } \\
\hline Male $(n=479)$ & $233(48.6)$ & $246(51.4)$ & $<0.0001$ \\
\hline Female $(n=560)$ & $144(25.7)$ & $416(74.3)$ & \\
\hline \multicolumn{4}{|l|}{ Age (y) } \\
\hline$\leq 24(n=244)$ & $62(25.4)$ & $182(74.6)$ & $<0.0001 *$ \\
\hline $25-44(n=405)$ & $182(44.9)$ & $223(55.1)$ & \\
\hline $45-64(n=276)$ & $112(40.6)$ & $164(59.5)$ & \\
\hline$\geq 65(n=114)$ & $21(18.4)$ & $93(81.6)$ & \\
\hline \multicolumn{4}{|l|}{ Education years } \\
\hline$\leq 6(n=29)$ & $4(13.8)$ & $25(86.2)$ & 0.016 \\
\hline $7-9(n=60)$ & $17(28.3)$ & $43(71.7)$ & \\
\hline $10-12(n=205)$ & $83(40.5)$ & $122(59.5)$ & \\
\hline$\geq 13(n=113)$ & $44(38.9)$ & $69(61.1)$ & \\
\hline \multicolumn{4}{|l|}{ Marital status } \\
\hline Single $(n=435)$ & $160(36.8)$ & $275(63.2)$ & 0.079 \\
\hline Married $(n=342)$ & $122(35.7)$ & $220(64.3)$ & \\
\hline Divorced/separated/widowed $(n=129)$ & $48(37.2)$ & $81(62.8)$ & \\
\hline Cohabitation $(n=18)$ & $12(66.7)$ & $6(33.3)$ & \\
\hline \multicolumn{4}{|l|}{ Economic activity } \\
\hline Unemployed $(n=295)$ & $96(32.5)$ & $199(67.5)$ & $<0.0001$ \\
\hline Employed $(n=312)$ & $154(49.4)$ & $158(50.6)$ & \\
\hline Student/housewife $(n=179)$ & $35(19.6)$ & $144(80.4)$ & \\
\hline \multicolumn{4}{|l|}{ Previous suicide attempt history } \\
\hline No $(n=399)$ & $121(30.3)$ & $278(69.7)$ & 0.001 \\
\hline Yes $(n=534)$ & $216(40.4)$ & $318(59.6)$ & \\
\hline \multicolumn{4}{|l|}{ Suicide plan } \\
\hline No $(n=653)$ & $141(21.6)$ & $512(78.4)$ & $<0.0001$ \\
\hline Yes $(n=284)$ & $189(66.5)$ & $95(33.5)$ & \\
\hline \multicolumn{4}{|l|}{ Gave notice before suicide attempt } \\
\hline No $(n=734)$ & $237(32.3)$ & $497(67.7)$ & 0.003 \\
\hline Yes $(n=51)$ & $27(52.9)$ & $24(47.1)$ & \\
\hline \multicolumn{4}{|l|}{ Psychiatric history } \\
\hline None $(n=477)$ & $224(47.0)$ & $253(53.0)$ & 0.003 \\
\hline Yes $(n=500)$ & $130(26.0)$ & $370(74.0)$ & \\
\hline
\end{tabular}

Values are presented as number (\%).

$\mathrm{cO}$, carbon monoxide.

* $p$-value was calculated using the chi-square test. All other $p$-values in this table were calculated using the Fisher's exact test.

patients between $25-44$ years of age and $41 \%$ of those between 45-64 years of age used the $\mathrm{CO}$ poisoning method compared with $25 \%$ of patients $\leq 24$ years of age and $18 \%$ of those $\geq 65$ years of age $(p<0.0001)$.

Approximately $49 \%$ of the economically active patients attempted suicide by $\mathrm{CO}$ poisoning, while a significantly smaller proportion of the patients who were students or housewives or unemployed chose $\mathrm{CO}$ poisoning as their suicide method $(\mathrm{p}<0.0001)$. Those who did not have suicide plans were much less likely to choose the $\mathrm{CO}$ poisoning method than those who had suicide plans ( $22 \%$ vs. $67 \%$; $p<0.0001$ ). Only $26 \%$ of the patients with a known history of psychiatric disorder were in the $\mathrm{CO}$ group compared to $47 \%$ of those with no history who chose the CO poisoning method ( $\mathrm{p}<0.001)$. 


\section{Differences in psychiatric diagnosis}

Table 2 summarizes the suicide attempters grouped according to the presence or absence of psychiatric diagnosis established by psychiatrists in the ED and, if present, based on individual diagnoses, which were then divided into the $\mathrm{CO}$ group and non- $\mathrm{CO}$ group.

Of the 1,039 suicide attempters, a psychiatric diagnosis was established in 592 patients of whom mood disorders were the most prevalent diagnosis $(n=357)$. Approximately $36 \%$ and $64 \%$ of the 357 patients with mood disorders attempted suicide by $\mathrm{CO}$ poisoning and a non-CO method, respectively, which was not significantly different compared to those with other psychiatric diagnoses combined $(\mathrm{p}=0.793)$.

Adjustment disorder was the second most prevalent disorder $(\mathrm{n}=123)$ among all suicide attempters. Of them, $47 \%$ used the CO poisoning method, which was statistically significantly higher than in patients with all other psychiatric diagnoses combined $(\mathrm{p}=0.004)$.

None of 23 suicide attempters with psychotic disorder employed the $\mathrm{CO}$ poisoning method, which was remarkably different compared to those with other psychiatric diagnoses $(\mathrm{p}<0.0001)$. Patients with personality disorder were also somewhat less likely to choose $\mathrm{CO}$ poisoning as the suicide method compared with those with other psychiatric diagnoses $(\mathrm{p}=0.046)$.

\section{Tendency to use $\mathrm{CO}$ poisoning}

The multivariable logistic regression analysis revealed that sex, age, the presence or absence of a suicide plan, and the presence or absence of psychiatric history were significant predictors for suicide using $\mathrm{CO}$ poisoning (Table 3). In our model, male were at 1.71 times higher tendency to choose $\mathrm{CO}$ poisoning over other methods (odds ratio [OR], 1.714; 95\% confidence interval [CI], $1.151-2.552 ; \mathrm{p}=0.008)$. In terms of age, patients younger than 65 years had a higher OR for suicide by CO poisoning than those aged 65 years or older. In particular, people aged 25-44 years had the highest OR for suicide by $\mathrm{CO}$ poisoning (OR, 7.350; 95\% CI, 3.332-16.212; $\mathrm{p}<0.001)$. With regard to the occupational status, employed individuals had higher a tendency to attempt suicide by $\mathrm{CO}$ poisoning than unemployed individuals $(\mathrm{p}=0.057)$. Those who plan to kill themselves after having suicidal ideation were also more likely to use $\mathrm{CO}$ poisoning as the suicide method than those who only had suicidal ideation (OR, 7.696; 95\% CI, 5.215-11.580). On the contrary, patients without a history of psychiatric diagnosis were more likely to choose $\mathrm{CO}$ poisoning as the suicide method (OR, 2.117; 95\% CI, 1.439-3.114; $\mathrm{p}<0.001)$.

\section{DISCUSSION}

This study showed that there were significant differences between suicide attempters by $\mathrm{CO}$ poisoning and those who used other suicide methods in terms of age, sex, marital status, economic activity status, the presence or absence of suicide attempt history, the presence or absence of suicide plan after having suicide ideation, the presence or absence of psychiatric history, and cur-

Table 2. Psychiatric diagnosis at the time of ED visit among those who attempted suicide by CO poisoning vs. Non-CO methods

\begin{tabular}{|c|c|c|c|}
\hline \multirow{2}{*}{ Psychiatric diagnosis } & \multicolumn{2}{|c|}{ Suicide methods } & \multirow{2}{*}{$\mathrm{p}$-value* } \\
\hline & CO poisoning $(n=211)$ & Non-CO methods $(n=381)$ & \\
\hline Mood disorders ( $n=357$ ) & $129(36.1)$ & $228(63.9)$ & 0.793 \\
\hline Adjustment disorders ( $n=123$ ) & $58(47.2)$ & $65(52.9)$ & 0.004 \\
\hline Anxiety disorders $(n=8)$ & $1(12.5)$ & $7(87.5)$ & 0.270 \\
\hline Personality disorders $(n=43)$ & $9(20.9)$ & $34(79.1)$ & 0.046 \\
\hline Psychotic disorders $(n=23)$ & $0(0.0)$ & $23(100.0)$ & $<0.0001$ \\
\hline Substance use disorders $(n=22)$ & $9(40.9)$ & $13(59.1)$ & 0.652 \\
\hline Unspecified $(n=16)$ & $5(31.3)$ & $11(68.8)$ & 0.797 \\
\hline
\end{tabular}

Values are presented as number (\%).

ED, emergency department; CO, carbon monoxide.

*Comparison of individual psychiatric diagnosis with all other psychiatric diagnoses combined. All p-values calculated using the Fisher's exact test. 
Table 3. ORs of suicide by CO poisoning by multivariable logistic regression

\begin{tabular}{|c|c|c|c|c|c|c|}
\hline \multirow{2}{*}{ Variable } & \multicolumn{3}{|c|}{ Univariable analysis } & \multicolumn{3}{|c|}{ Multivariable analysis } \\
\hline & OR & $95 \% \mathrm{Cl}$ & $p$-value & OR & $95 \% \mathrm{Cl}$ & $p$-value \\
\hline \multicolumn{7}{|l|}{ Sex } \\
\hline Female & 1.00 & & & 1.00 & & \\
\hline Male & 2.736 & $2.108-3.552$ & $<0.001$ & 1.714 & $1.151-2.552$ & 0.008 \\
\hline \multicolumn{7}{|l|}{ Age $(y)$} \\
\hline$\leq 24$ & 1.509 & $0.867-2.626$ & 0.146 & 3.702 & $1.565-1.565$ & 0.003 \\
\hline $25-44$ & 3.614 & $2.165-6.033$ & $<0.001$ & 7.350 & $3.332-16.212$ & $<0.001$ \\
\hline $45-64$ & 3.024 & $1.778-5.143$ & $<0.001$ & 4.948 & $2.185-2.186$ & $<0.001$ \\
\hline$\geq 65$ & 1.000 & & & 1.000 & & \\
\hline \multicolumn{7}{|l|}{ Education years } \\
\hline$\leq 6(n=29)$ & 0.251 & $0.082-0.770$ & 0.016 & & & \\
\hline $7-9(n=60)$ & 0.620 & $0.315-1.220$ & 0.166 & & & \\
\hline $10-12(n=205)$ & 1.067 & $0.667-1.707$ & 0.787 & & & \\
\hline$>12(n=113)$ & 1.000 & & & & & \\
\hline \multicolumn{7}{|l|}{ Marital status } \\
\hline Single $(n=435)$ & 1.000 & & & & & \\
\hline Married $(n=342)$ & 0.953 & $0.710-1.280$ & 0.750 & & & \\
\hline Divorced/separated/widowed $(n=129)$ & 1.019 & $0.678-1.530$ & 0.930 & & & \\
\hline Cohabitation $(n=18)$ & 3.437 & $1.266-9.336$ & 0.015 & & & \\
\hline \multicolumn{7}{|l|}{ Economic activity } \\
\hline Employed & 2.020 & $1.453-2.809$ & $<0.001$ & 1.512 & $0.987-2.316$ & 0.057 \\
\hline Student/housewife & 0.504 & $0.324-0.784$ & 0.002 & 0.501 & $0.267-0.940$ & 0.031 \\
\hline Unemployed & 1.000 & & & 1.000 & & \\
\hline \multicolumn{7}{|l|}{ Suicide plan } \\
\hline Yes & 7.224 & $5.304-9.840$ & $<0.001$ & 7.696 & $5.115-11.580$ & $<0.001$ \\
\hline No & 1.000 & & & 1.000 & & \\
\hline \multicolumn{7}{|l|}{ Psychiatric history } \\
\hline Yes & 1.000 & & & 1.000 & & \\
\hline No & 2.520 & $1.926-3.597$ & $<0.001$ & 2.117 & $1.439-3.114$ & $<0.001$ \\
\hline \multicolumn{7}{|l|}{ Previous suicide attempt } \\
\hline Yes & 1.561 & $1.186-2.054$ & 0.001 & 1.188 & $0.220-1.188$ & 0.435 \\
\hline No & 1.000 & & & & & \\
\hline
\end{tabular}

OR, odds ratio; $\mathrm{CO}$, carbon monoxide; $\mathrm{Cl}$, confidence interval.

rent psychiatric diagnosis.

It was previously shown that male are more likely to kill themselves by $\mathrm{CO}$ poisoning than female $[10,14,21,22]$. A study also demonstrated that the ratio of male to female in the $\mathrm{CO}$ group was significantly higher than in the non-CO group among suicide attempters [9]. Our study supports previous results. In our study, male were 1.714 times more likely than female to use $\mathrm{CO}$ poisoning when attempting suicide.

Among all age groups mentioned in our study, individuals below the age of 65 years (especially those between 25-44 years) had a higher tendency to use $\mathrm{CO}$ poisoning when attempting suicide than those aged 65 years and older. Although our study was targeted to suicide survivors, our results are in line with previously published results from studies of suicide victims [10,14,21]. Indeed, a previous study also showed that there was no significant difference in the sociodemographic characteristics between those who survived and those who eventually died following suicide attempts using CO poisoning [10].

In addition, people who had a suicidal plan were more likely to choose CO poisoning compared to those who had only suicide ideation without a plan. Similarly, Tsai et al. [11] reported that people who attempted suicide by 
$\mathrm{CO}$ poisoning had more extensive preparation than those by substance poisoning. In order to attempt suicide by $\mathrm{CO}$ poisoning, one must obtain materials such as charcoal to burn. In addition, associated tools and limited space are required to efficiently generate $\mathrm{CO}$. Since it requires some time to prepare all of these, suicide attempts using CO poisoning would most likely be planned acts rather than impulsive attempts.

Significant differences in economic activity were found between the $\mathrm{CO}$ and non-CO groups. The multivariable logistic regression analysis of our data showed that employed individuals had a higher tendency to use $\mathrm{CO}$ poisoning as the suicide method than unemployed individuals and students/housewives. However, a study from Japan showed that there were no significant differences between the employed and unemployed groups [9]. These conflicting results may have been due to a sigificant difference in the sample size, i.e., 762 patients in the Non-CO group in our study vs. only 20 patients in the Non-CO group in their study, and also due to the fact that we performed a multivariable logistic regression analysis, while they did not.

In our study, the tendency of suicide attempts by $\mathrm{CO}$ poisoning was higher in people with no known history of psychiatric disorders before suicide attempts. Interestingly, Kato et al. [9] also reported that the proportion of patients with a psychiatric history was significantly lower in the $\mathrm{CO}$ group than in the non-CO group, but all patients in the $\mathrm{CO}$ group were diagnosed with mental health disorders by structured interviews after admission. Similarly, many of patients without history of psychiatric disorders before the ED visit in our study were eventually diagnosed as having a psychiatric disorder at the ED by psychiatrists. Given these results, one may assume that a considerable number of suicide attempters in the CO poisoning group did not seek mental health care although they were having mental health issues. The gender gap may be one of the explanations of this phenomenon. Traditional masculinity has been reported to be a key risk factor for male vulnerability promoting maladaptive coping strategies such as emotional unexpressiveness, reluctance to seek mental health care, etc [23]. Indeed, among suicide attempters in our study, male were more likely than female to have no history of psychiatric disorders $(60 \%$ vs. $40 \%, \mathrm{p}<0.00001$ by Fisher's exact test; the detailed results not presented in the Results section). Previous studies [9,23] as well as the results of the present study highlight the need for promoting to go to mental health care and improved access to mental health services.

A study conducted in Taiwan found that mood disorders, including depressive disorders, accounted for the largest proportion of psychiatric diagnoses in the $\mathrm{CO}$ poisoning suicide group [18]. While this study included a fair number of suicide attempters $(n=106)$, there was no comparison group, e.g., non-CO group. Therefore, one could not draw any conclusion as to whether or not a mood disorder is a predictor for using $\mathrm{CO}$ poisoning as the suicide method. On the other hand, a study conducted in Japan included a non-CO group. In this study, the proportion of patients with mood disorders was reported to be significantly higher in the $\mathrm{CO}$ poisoning suicide group $(13 / 20,65.0 \%)$ than that in the other methods group (194/627, 30.9\%) [9]. While these results may be viewed as mood disorders being a predicting factor for using $\mathrm{CO}$ poisoning as the suicide method, we feel that caution should be taken given that the total number of suicide attempters using $\mathrm{CO}$ poisoning in that study was only 20. In contrast, our study included 211 patients in the $\mathrm{CO}$ group and 381 patients in the non- $\mathrm{CO}$ group; these numbers are not only high but also well-balanced between the two groups. While we also found mood disorders to account for the highest proportion in the $\mathrm{CO}$ group as found by previous studies, mood disorders accounted also for the highest proportion in the non-CO group with no significant difference between the two groups. Our results seem to indicate that mood disorders are most common among all suicide attempters irrespective of the type of the suicide method utilized.

We found that adjustment disorders accounted for the second-highest proportion in both the $\mathrm{CO}$ and non- $\mathrm{CO}$ groups. However, the proportion of $\mathrm{CO}$ groups among patients with adjustment disorders was significantly higher compared to those with other psychiatric diagnoses. One of the most remarkable results of our study was that none of the 23 patients with psychosis chose the $\mathrm{CO}$ poisoning method. Also, patients with personality disorders were somewhat less likely to choose CO poisoning as the suicide method. This result may suggest the possibility that patients with unstable emotions are less likely to use $\mathrm{CO}$ poisoning given that the emotions of patients with personality disorders often change more rapidly than other patients.

In Confucianism, the body inherited from the parents should cherish, and causing no physical damage to the body is considered to be the beginning of filial piety 
[24]. Given this cultural background, a previous study suggested that a high prevalence of $\mathrm{CO}$ poisoning might have to do with the practice of Confucianism in Asia as suicide by $\mathrm{CO}$ poisoning causes no significant external damage than many other lethal suicide methods [14]. However, Confucianism has been around for a very long time even before the prevalence of suicide by $\mathrm{CO}$ poisoning began to increase abruptly. Further, Confucianism is fading in modern times, especially among the young generation. For these reasons, we do not believe that Confucianism has played any significant role in the increased prevalence of suicide by $\mathrm{CO}$ poisoning. Instead, we believe that people, especially the younger generation, who were having suicidal ideation were heavily influenced by the fact that celebrities in Hong Kong and Korea took their own life using $\mathrm{CO}$ poisoning and also by extensive coverage by the media $[15,25,26]$. This is further supported by results from a study that a recall of a scene from a television broadcast of someone's suicide was the most common determinant of suicide methods, suggesting a great influence of the media on the choice of the suicide method [27].

Although $\mathrm{CO}$ poisoning causes minor external visible damage, it can cause serious internal damage, including neurological damage. Most notably, delayed brain syndrome can occur, which causes cognitive impairment and neurological changes that gradually develop after recovery from acute poisoning. It can also occur as long as 6 years after $\mathrm{CO}$ gas exposure $[28,29]$. Therefore, $\mathrm{CO}$ poisoning should not be overlooked, and for which early intervention is warranted. Given the low frequency of seeking mental health care in the CO group, investigators have felt that community-based approaches might be relevant in the prevention of suicides by $\mathrm{CO}$ poisoning [11]. Restricting access to obtaining charcoals, improvements in the quality of charcoal, and more judicious media coverage have been discussed. Indeed, the effectiveness of restricting access to obtaining charcoals was demonstrated by a study from Hong Kong which compared suicide rates in two adjoining districts which implemented different levels of regulations/restrictions on charcoal sales; it was difficult to purchase charcoal from retail stores in one district whereas it was not in the other district. This study found a significant difference in the suicide rates using $\mathrm{CO}$ poisoning between the two districts [30]. In the 1960s, inhalation of gases from the exhaust system of a car's petrol engine was a common method of suicide in young male in the United States and the United Kingdom. After implementing new toxic regulations, catalytic converters reducing $\mathrm{CO}$ emissions were introduced, which resulted in a decreased rate of deaths from suicide [31,32]. In Korea, an agreement was made between the Korea Suicide Prevention Center and the Korea Supermarkets Alliance in 2018; it was highly recommended that burning ignition coal be sold on a non-display basis. To minimize the influence of the media, the Ministry of Health and Welfare revised the "Suicide Report Recommendation Criteria" in 2018 and prohibited the provision of stimulating and detailed descriptions [33]. Future studies will show how effective these measures implemented in Korea are in decreasing suicides by $\mathrm{CO}$ poisoning. In the meantime, more effective preventive measures may be developed based on the risks and the more vulnerable populations identified by the current study and other studies.

This study has a few limitations. Firstly, we only included survivors of suicide attempts, and people who died from suicide were excluded. Since it is known that the people who have attempted suicide and those who have killed themselves are quite different in their background profiles $[34,35]$, further studies will be needed to clarify the differences between suicide attempters and the victims who used $\mathrm{CO}$ poisoning suicides. Secondly, because this study was conducted in a single center, the results of this study may not be generalizable. Thirdly, because we devided the group into the $\mathrm{CO}$ group and non-CO group, the comparison group could be heterogenous. However, as there has been a rapid increase in the rate of suicide attempt using $\mathrm{CO}$ poisoning in Korea, and this marked increase in suicide attempt using $\mathrm{CO}$ poisoning was not offset by a decrease in suicide attempts by any other methods that have remained relatively stable. Lastly, as a retrospective study, some initial assessments included insufficient information depending on the condition of the patient and the degree of cooperation. Despite these limitations, to our knowledge, this study included the largest number of suicide attempters by $\mathrm{CO}$ poisoning directly evaluated in a clinical setting instead of obtaining data from a registry. In addition, there were only three emergency medical facilities that could operate high-pressure oxygen chambers in downtown Seoul, a city with a population of 10 million people. For these reasons, we believe that the results of this study, despite being a single-center study, can probably be generalizable to those who attempted $\mathrm{CO}$ poisoning. 


\section{CONCLUSION}

Among suicide attempters in Korea, the tendency to use $\mathrm{CO}$ poisoning as the suicide method was more pronounced in male, adults aged 25-64 years (especially 25-44 years), those who are employed, those who have a suicidal plan after having suicidal ideation, and those with no history of psychiatric diagnosis before the ED visit. Patients with adjustment disorder were more likely and those with psychosis were unlikely to use $\mathrm{CO}$ poisoning as the suicide method compared to those with other psychiatric diagnoses. To prevent the $\mathrm{CO}$ poisoning suicide attempt, it seems warranted to develop a tool to screen those with a suicide risk as part of the regular health checkup so that early intervention may be provided. Also, it would be necessary to improve society's awareness of the importance of seeking psychiatric/ mental health care.

\section{CONFLICTS OF INTEREST}

The authors have nothing to disclose.

\section{ACKNOWLEDGEMENTS}

The authors are grateful to the members of "Saving Life Teams". We also would like to extend our thanks to Prof. Chun Ki Kim of the Hanyang University College of Medicine for his review of the manuscript and valuable feedback.

\section{ORCID}

Hwayeon Jo
https://orcid.org/0000-0002-3226-3396
Kounseok Lee
https://orcid.org/0000-0002-6084-5043
Sujin Son
https://orcid.org/0000-0001-5005-0688
Hyunggoo Kang
https://orcid.org/0000-0002-9522-2532
Seokhyeon Kim
https://orcid.org/0000-0002-0530-8026
Sungwon Roh
https://orcid.org/0000-0003-4557-3542

\section{REFERENCES}

1. World Health Organization. LIVE LIFE: preventing suicide. Geneva: World Health Organization; 2018.

2. Organisation for Economic Cooperation and Development. Suicide rates [Internet]. Paris: Organization for Economic Cooperation and Development; 2020 Jan 19 [cited 2020 Jan 19]. Available from: https://data.oecd.org/healthstat/suiciderates.htm.

3. Statistics Korea. The cause of death statistics [Internet]. Daejeon: Statistics Korea; 2019 Sep 24 [cited 2020 Mar 8]. Available from: https://mdis.kostat.go.kr/extract/extYearsSurvSearchNew.do?curMenuNo=UI_POR_P9012.

4. Statistics Korea. Annual report on the cause of death statistics [Internet]. Daejeon: Statistics Korea; 2019 Sep 24 [cited 2020 Jan 19]. Available from: https://kosis.kr/publication/ publicationThema.do?pubcode $=\mathrm{YD}$.

5. Hyun KR, Lee SM, Choi KC, Lee SY, Kim JY. Analysis of socioeconomic cost of major diseases for setting health security policy priorities. Wonju: National Health Insurance Service; 2014.

6. Kim SW, Jhon M, Kim M, Paik JW, Kim JM, Yoon JS. A social psychiatric approach to suicide prevention. J Korean Med Assoc 2019;62:93-101.

7. Ministry of Health and Welfare. 2013 National survey on suicide. Sejong: Ministry of Health and Welfare; 2014.

8. Ministry of Health and Welfare. 2018 National survey on suicide. Sejong: Ministry of Health and Welfare; 2019.

9. Kato K, Akama F, Yamada K, Maehara M, Kimoto K, Kimoto K, et al. Frequency and clinical features of patients who attempted suicide by charcoal burning in Japan. J Affect Disord 2013;145:133-5.

10. Chan KP, Yip PS, Au J, Lee DT. Charcoal-burning suicide in post-transition Hong Kong. Br J Psychiatry 2005;186:6773.

11. Tsai CW, Gunnell D, Chou YH, Kuo CJ, Lee MB, Chen YY. Why do people choose charcoal burning as a method of suicide? An interview based study of survivors in Taiwan. J Affect Disord 2011;131:402-7.

12. Liu KY, Beautrais A, Caine E, Chan K, Chao A, Conwell $\mathrm{Y}$, et al. Charcoal burning suicides in Hong Kong and urban Taiwan: an illustration of the impact of a novel suicide method on overall regional rates. J Epidemiol Community Health 2007;61:248-53.

13. Yip PS, Lee DT. Charcoal-burning suicides and strategies for prevention. Crisis 2007;28 Suppl 1:21-7.

14. Pan YJ, Liao SC, Lee MB. Suicide by charcoal burning in Taiwan, 1995-2006. J Affect Disord 2010;120:254-7.

15. Lee AR, Ahn MH, Lee TY, Park S, Hong JP. Rapid spread of suicide by charcoal burning from 2007 to 2011 in Korea. Psychiatry Res 2014;219:518-24.

16. Chen YY, Yip PS, Chan CH, Fu KW, Chang SS, Lee WJ, et al. The impact of a celebrity's suicide on the introduction and establishment of a new method of suicide in South Ko- 
rea. Arch Suicide Res 2014;18:221-6.

17. Choi YR, Cha ES, Chang SS, Khang YH, Lee WJ. Suicide from carbon monoxide poisoning in South Korea: 20062012. J Affect Disord 2014;167:322-5.

18. Lin C, Yen TH, Juang YY, Leong WC, Hung HM, $\mathrm{Ku} \mathrm{CH}$, et al. Comorbid psychiatric diagnoses in suicide attempt by charcoal burning: a 10-year study in a general hospital in Taiwan. Gen Hosp Psychiatry 2012;34:552-6.

19. American Psychiatric Association. Diagnostic and statistical manual of mental disorders. Washington, D.C: American Psychiatric Association; 2013.

20. World Health Organization. International statistical classification of diseases and related health problems. Geneva: World Health Organization; 2019.

21. Ji NJ, Hong YP, Stack SJ, Lee WY. Trends and risk factors of the epidemic of charcoal burning suicide in a recent decade among Korean people. J Korean Med Sci 2014;29:1174-7.

22. Chen YY, Yip PS, Lee CK, Gunnell D, Wu KC. The diffusion of a new method of suicide: charcoal-burning suicide in Hong Kong and Taiwan. Soc Psychiatry Psychiatr Epidemiol 2015;50:227-36.

23. Möller-Leimkühler AM. The gender gap in suicide and premature death or: why are men so vulnerable? Eur Arch Psychiatry Clin Neurosci 2003;253:1-8.

24. Chen I. The book of filial duty. Whitefish: Kessinger Publishing, LLC; 2010.

25. Yang AC, Tsai SJ, Yang CH, Shia BC, Fuh JL, Wang SJ, et al. Suicide and media reporting: a longitudinal and spatial analysis. Soc Psychiatry Psychiatr Epidemiol 2013;48:42735 .

26. Lee DT, Chan KP, Lee S, Yip PS. Burning charcoal: a novel and contagious method of suicide in Asia. Arch Gen Psy- chiatry 2002;59:293-4.

27. Kim JY, Hong JP, Hwang JW, Jhoo JH, Kyeon YG, Lee K. Retrospective recall study about psychological and behavioral characteristics in high lethality suicide attempters. J Korean Neuropsychiatr Assoc 2015;54:435-43.

28. Thom SR, Taber RL, Mendiguren II, Clark JM, Hardy KR, Fisher AB. Delayed neuropsychologic sequelae after carbon monoxide poisoning: prevention by treatment with hyperbaric oxygen. Ann Emerg Med 1995;25:474-80.

29. Sohn YH, Jeong Y, Kim HS, Im JH, Kim JS. The brain lesion responsible for parkinsonism after carbon monoxide poisoning. Arch Neurol 2000;57:1214-8.

30. Yip PS, Law CK, Fu KW, Law YW, Wong PW, Xu Y. Restricting the means of suicide by charcoal burning. Br J Psychiatry 2010;196:241-2.

31. Amos T, Appleby L, Kiernan K. Changes in rates of suicide by car exhaust asphyxiation in England and Wales. Psychol Med 2001;31:935-9.

32. Mott JA, Wolfe MI, Alverson CJ, Macdonald SC, Bailey $\mathrm{CR}$, Ball LB, et al. National vehicle emissions policies and practices and declining US carbon monoxide-related mortality. JAMA 2002;288:988-95.

33. Ministry of Health and Welfare. Suicide report recommendation criteria. ver. 3.0. Sejong: Ministry of Health and Welfare; 2018.

34. Joo SH, Wang SM, Kim TW, Seo HJ, Jeong JH, Han JH, et al. Factors associated with suicide completion: a comparison between suicide attempters and completers. Asia Pac Psychiatry 2016;8:80-6.

35. DeJong TM, Overholser JC, Stockmeier CA. Apples to oranges?: a direct comparison between suicide attempters and suicide completers. J Affect Disord 2010;124:90-7. 